\title{
A solution to the ossification of community psychiatry
}

\author{
Peter Tyrer $^{1}$
}

The Psychiatrist (2013), 37, 336-339, doi: 10.1192/pb.bp.113.042937

${ }^{1}$ Imperial College London

Correspondence to Peter Tyrer (p.tyrer@imperial.ac.uk)

First received 29 Jan 2013, final revision 6 May 2013, accepted 15 May 2013

\begin{abstract}
Summary The aim for seamless care that has long been the ultimate goal of good community psychiatry in the UK has disappeared, and there is now much needless argument over models of delivering care that ignore its main philosophy. It is argued that this ossification of care has not only made it ineffective, but has also promoted demoralisation and burn-out in the workforce, as the locus of control has shifted from clinician to managerial imperative. An initiative that can break up the opaque structures that hinder continuity of care is now available and a suggestion is made for a flexible, invigorated community care team system based on smaller catchment areas that allows a single team to combine the elements of assertive outreach, crisis resolution and early intervention with in-patient care.
\end{abstract}

Declaration of interest P.T. was a consultant with an assertive outreach team until 2009. He was also Editor of the British Journal of Psychiatry at the time of writing, but this has had no influence in the assessment of this paper.

\section{Highs and lows of community psychiatry}

In a perceptive article written 17 years ago, Sumathipala \& Hanwella ${ }^{1}$ described what they called a spiral of community care. This was derived from evidence over a long time period that society alternates between embracing community psychiatry as an inclusive and positive way of treating the mentally ill, and an exclusive psychiatry at other times, when those with mental illness are perceived as dangerous or problematic in other ways and therefore detained in institutions of one sort or the other. I think this hypothesis has credence and, if you look around the world, you can find evidence of societies in which both the inclusive and exclusive models are being practised. For example, Japan in recent years has consistently practised the exclusion model. Most people with significant mental illness, particularly that which handicaps their ability to fit in with what is a well-ordered society, are placed in institutions. Many of these institutions are not mental hospitals, and some are quite benign in their practice, not least because many Japanese patients who have serious mental illness appear to accept this way of life without questioning or railing against it. ${ }^{2}$ Other societies, particularly those in low-income countries, have never been able to practise 'exclusive psychiatry' because they do not have the institutions to house those with severe mental illness.

Where are we now in what we would like to consider are the more enlightened countries? The early gloss has gone off the excitement of community psychiatry and the focus has been more on excluding people from hospital than providing good community care. The general mantra of 'community psychiatry good, hospital psychiatry bad' has been a two-edged sword, for although it has promoted the development of many community psychiatric services, it has also led to the neglect of the proper function of in-patient care, a combination of asylum and rehabilitation, and today may have reached a point where a fundamental wish to improve patients' autonomy is being removed by an overbureaucratised system of community care that is obsessed by risk, and in danger of promoting greater institutionalisation by a complex regulatory framework that denies the flexibility that is essential to good community psychiatric practice. As a consequence, patient autonomy has been reduced and involuntary admission rates have risen across Europe, leading to urgency in the need for a solution. ${ }^{3}$ Where in the UK community psychiatry used to be flexible, adventurous, creative and bold, with the many changes imposed from policy managers in recent years it has become constricted, controlled, limiting and self-serving. Autonomy for practitioners has almost entirely disappeared and been replaced by a rigid system of care that leads to patients encountering a bewildering number of health professionals, who carry out specific regimented tasks but who rarely have the chance to develop meaningful relationships with the people they treat.

In the full flower of community psychiatry, perhaps best expressed in the 1975 government White Paper, Better Services for the Mentally Ill, ${ }^{4}$ there was no limit put on the extent to which community psychiatry might extend. The policy suffered through having no clear costings or time scales, but the intention was to gradually close down mental hospitals, improve the links between primary and secondary care, and practise what is nowadays called 'localism', developing treatment as much as possible in smaller areas where needs could be identified and staff could be 
responsive to these needs, an organisational structure rather like a beehive. ${ }^{5}$ There were no restrictions placed on this expansion, and professionals took it upon themselves to make changes, including the expansion of day care, training of general practitioners in psychotherapy, and opening up psychiatric clinics in primary care, ${ }^{6-8}$ so that in some parts of the UK they became the norm. ${ }^{9}$

Most of these initiatives were profession led, and because they depended on the enthusiasm of individuals, their implementation was patchy across the country. It was therefore natural that further legislation would be necessary to formalise community psychiatry. The introduction of the care programme approach ${ }^{10}$ (and later its enhanced version) was the first of these, followed by the adoption of assertive outreach teams, crisis resolution and home treatment services, and early intervention services initiated by the National Service Framework for Mental Health.

\section{Three aspects of reform in healthcare}

It is not the purpose of this paper to comment on the merits and handicaps of these formalised models of community care, except to point out three universal aspects that are often forgotten. First, even the best of reforms, usually introduced before evidence of their efficacy in the chosen setting is available, disrupt existing patterns of care that may be working well. Second, initial enthusiasm for anything new sets a process in motion that can easily give a wrong impression of success. Every new service is promoted heavily, often with an increase of resources and shiny new premises, and many staff, now a little bored with a 'standard' service that has lost its shine, are encouraged to apply for a post within the new scheme. There is competition for these new posts, the best of the staff from the existing services are appointed, leading to a loss of the most valuable expertise in the older services, and any comparisons between the old and new models automatically favour the new approach. But it is not the new model that makes the results superior; it is just that the staff are better skilled and, at least temporarily, more motivated. Third, every new reform adds another layer to the bureaucracy of care ${ }^{11}$ so less and less time is spent in patient contact.

These three deficiencies of reform are often forgotten. Instead, the product champions of the different service models spend large amounts of unproductive time assaulting each other in increasingly intemperate language ${ }^{12,13}$ forgetting that they are all meant to be fighting on the same side. The growth of specialisation then leads to greater fragmentation of care, ${ }^{14,15}$ so that it is now possible for a patient to be under four or five different consultants during the course of a single episode of illness. With greater fragmentation there is the increased bureaucracy of transfer between teams, which also takes up a large proportion of clinical time that would be best spent in clinical contact.

\section{The way forward to a solution}

The development of community mental health teams was not in any way a planned process. As a consequence, the resources given were never allocated in a way that allowed the full expression of the needs of a comprehensive service to be realised. Assertive outreach and crisis resolution services were introduced as a patched-up recognition of this inadequacy, but the mistake made was to pretend that special skills were needed to perform these extra tasks. Neither assertive nor crisis treatment need extra expertise that generic community mental health teams do not possess; all professionals in these teams should have them, and it downgrades the professionalism of the community mental health practitioner to pretend otherwise. ${ }^{16}$ The simple explanation why assertive treatments do not have any important advantages over standard care is that they offer nothing new, and repeatedly trying to give them extra tasks for high-risk patients is doomed to fail unless they are given some level of greater expertise. ${ }^{17}$

It was also never intended, at least at the onset of community mental health services, to separate community mental health teams from in-patient services. Indeed, the need to integrate community and hospital care was a core principle of this initiative and this reduced not only in-patient care but also mortality. ${ }^{18}$ We now need to return to the old principles of community psychiatry, an environment where practitioners feel supported by their colleagues, have a varied case-load, including intensive intervention and crisis care when appropriate, demonstrate continuity of care by keeping in contact with their patients when they enter institutional care of any sort, including prison, and can use in-patient care wisely, with short-term respite when needed. They should be allowed to practise without managers, who have much less awareness and sophistication, exercising control and making non-clinical arbitrary decisions that, at best, interfere with good care and, at worst, sabotage it altogether. The current creaking structure groaning at its joints needs a well-oiled overhaul.

\section{Need for reorganisation of community teams}

It is not good enough to blame the present problems in community care on the economic downturn; they had developed long before the economic climate changed. In any case, the evidence shows that good community care is cost-effective and so is even more needed nowadays. Cost-effectiveness is rarely achieved by practitioners being heavily monitored and wasting valuable time in activities that have nothing to do with direct patient care. It is achieved by services that are patient led and therefore flexible, following the individual pathway necessary without it being imposed by a uniform generic automaton generated from an impersonal health guideline. The way community psychiatry can free itself from its ossifying bonds is to remind itself of its core principles of good care, which are also heavily endorsed by the patients who receive it. Thus:

(a) if good facilities are available for patients to be treated outside hospital, they should be used as much as possible;

(b) if a hospital bed is necessary it should be available when required and should be as close as possible to the patient's home; hospital should be able to serve as a place of refuge and respite as well as a treatment centre; 
(c) continuity of care may not always be possible but should be striven for as a matter of principle, and all community teams should stay in touch with their patients no matter where they are placed;

(d) individual or team-based treatment both have merits and their choice should be determined in collaboration with the patient and his or her carers, and maintained irrespective of treatment setting.

All these principles are being undermined at present. In particular, avoidance of admission has not only become more important but now almost seems to be equated with good community care. When admission does take place there is frequent discontinuity, and individual therapeutic relationships are extremely difficult to develop and maintain. $^{14,15}$ It needs to be appreciated that it is not the model of care that helps patients - it is the practitioners who provide the treatment. Shoe-horning them into one team structure after another, often increasing their case-loads in the process, does nothing for their morale or performance. ${ }^{19}$

Changing the system is not just a pipe dream; the community practitioners are fighting back. The principles of good care can still be practised in the community mental health team, the unsung 'control' treatment in many studies that remains a highly cost-effective form of care ${ }^{20,21}$ and the necessary flexibility to maintain continuity can be provided in a team structure that allows all elements of early intervention, assertive outreach, crisis resolution and recovery to be practised at appropriate times in the course of a patient's care.

Although such a completely comprehensive team remains elusive, it has a successful evidence-based pedigree. ${ }^{22}$ This can only be achieved by allowing greater autonomy within teams to maintain priorities, reducing the size of the catchment area for each team so that they do not become overwhelmed and depersonalised in their attitudes, ${ }^{19}$ and by refreshing staff members with different attachments within the team so they do not develop repetitive impersonal practices. This can be done within the present structure of UK services as there are now so many specialised teams.

The recent adoption of a similar approach has attracted great support in both community and liaison psychiatry. ${ }^{23,24}$ In this model, all elements of good liaison and community care can be combined and deployed when needed, and the clinicians in the services also have a more satisfying working relationship with patients with a greater degree of variety than at present. This does not mean that specialist teams are unnecessary, particularly for some in-patients such as those in longer-term rehabilitation, and for other disorders ${ }^{25,26}$ where there is much room for improvement, but for acute care an integrated system makes better use of expertise and brings community and hospital services together. The rotation of professionals within different parts of the team helps in the development of comprehensive skills, so that they do not become fixed in their views and can at least understand the viewpoint of the patients who pass through the many hoops of psychiatric care. The current separation of in-patient from community services needs to be reversed, and the greater degree of liaison between these teams recently suggested in the $\mathrm{USA}^{27}$ could be achieved with better use of in-patient beds. As rotation of team members to new functions across different geographically based services has been implemented successfully in the past, ${ }^{28}$ it should not represent a problem within community teams. Such a test programme could be implemented in closely knit communities with good cross-service links such as those in Northern Ireland. This, I predict with some confidence, would not only be cost-effective but would raise the morale of a service that has been relegated to the backwaters of care for too long.

\section{About the author}

Peter Tyrer is Professor of Community Psychiatry, Department of Psychological Medicine, Division of Neuroscience and Psychological Medicine, Imperial College London, UK.

\section{References}

1 Sumathipala A, Hanwella R. The evolution of psychiatric care - a spiral model. Psychiatr Bull 1996; 20: 561-3.

2 Ito $\mathrm{H}$, Setoya $\mathrm{Y}$, Suzuki $\mathrm{Y}$. Lessons learned in developing community mental health care in East and South East Asia. World Psychiatry 2012; 11: $186-90$.

3 Fiorillo A, De Rosa C, Del Vecchio V, Jurjanz L, Schnall K, Onchev G, et al. How to improve clinical practice on involuntary hospital admissions of psychiatric patients: suggestions from the EUNOMIA study. Eur Psychiatry 2011; 26: 201-7.

4 Department of Health and Social Security. Better Services for the Mentally III. HMSO, 1975.

5 Tyrer P. The hive system. A model for a psychiatric service. Br J Psychiatry 1985; 146: 571-5.

6 Brook A, Bleasdale JK, Dowling J, Hopkins JH, Pollard CJ, Stroud RA. An experiment in general practitioner-psychiatrist cooperation. J Coll Gen Pract 1966; 11: 184-94.

7 Mitchell AR. Psychiatrists in primary health care settings. Br J Psychiatry 1985; 147: 371-9.

8 Creed F, Black D, Anthony P, Osborn M, Thomas P, Tomenson B. Randomised controlled trial of day patient versus inpatient psychiatric treatment. BMJ 1990; 300: 1033-7.

9 Pullen IM, Yellowlees AJ. Scottish psychiatrists in primary health-care settings. A silent majority. Br J Psychiatry 1988; 153: 663-6.

10 Kingdon D. Care programme approach. Recent government policy and legislation. Psychiatr Bull 1994; 18: 68-70.

11 Kingdon D. Reclaiming the care programme approach. Psychiatr Bull 1998; 22: 341.

12 Sashidharan SP, Smyth M, Owen A. PRiSM Psychosis Study. Thro'a glass darkly: a distorted appraisal of community care. Br J Psychiatry 1999; 175: 504-7.

13 Rosen A, Stein LI, McGorry P, Harvey C, Birchwood M, Diamond R. Specialist community teams backed by years of quality research. Psychiatrist 2013; 37: 38.

14 Lodge G. How did we let it come to this? A plea for the principle of continuity of care. Psychiatrist 2012; 36: 361-3.

15 Burns T. The dog that failed to bark. Psychiatrist 2010; 34: 361-3.

16 Tyrer P. Effectiveness of intensive treatment in severe mental illness. $\mathrm{Br} J$ Psychiatry 2000; 176: 492-3.

17 Morthorst B, Krogh J, Erlangsen A, Alberdi F, Nordentoft M. Effect of assertive outreach after suicide attempt in the AID (assertive intervention for deliberate self harm) trial: randomised controlled trial. BMJ 2012; 345: e4972.

18 Simmonds S, Coid J, Joseph P, Marriott S, Tyrer P. Community mental health team management in severe mental illness: a systematic review. Br J Psychiatry 2001; 178: 497-502. 
19 Johnson S, Osborn DPJ, Araya R, Wearn E, Paul M, Stafford M, et al. Morale in the English mental health workforce: questionnaire survey. $B$ J Psychiatry 2012; 201: 239-46.

20 Malone D, Marriott S, Newton-Howes G, Simmonds S, Tyrer P. Community mental health teams for people with severe menta illnesses and disordered personality. Schizophr Bull 2009; 35: 13-4.

21 Onyett S, Tyrer P, Connolly J, Malone S, Rennison J, Parslow S, et al. The Early Intervention Service: the first 18 months of an Inner London demonstration project. Psychiatr Bull 1990; 14: 267-9.

22 Merson S, Tyrer P, Onyett S, Lynch S, Lack S, Johnson AL. Early intervention in psychiatric emergencies: a controlled clinical trial. Lancet 1992; 339: 1311-4

23 Tadros G, Salama RA, Kingston P, Musafa N, Johnson E, Pannell R, et al. Impact of an integrated rapid response psychiatric liaison team on quality improvement and cost savings: the Birmingham RAID model. Psychiatrist 2013; 37: 4-10.
24 Firn $M$, Hindhaugh $K$, Hubbeling D, Davies G, Jones B, White SJ. A dismantling study of assertive outreach services: comparing activity and outcomes following replacement with the FACT model. Soc Psychiatry Psychiatr Epidemiol 2013; 48: 997-1003.

25 Killaspy H, Marston L, Omar RZ, Green N, Harrison I, Lean M, et al. Service quality and clinical outcomes: an example from mental health rehabilitation services in England. Br J Psychiatry 2013; 202: 28-34.

26 Taylor TL, Killaspy H, Wright C, Turton P, White S, Kallert TW, et al. A systematic review of the international published literature relating to quality of institutional care for people with longer term mental health problems. BMC Psychiatry 2009; 9: 55.

27 Glick ID, Sharfstein SS, Schwartz HI. Inpatient psychiatric care in the 21st century: the need for reform. Psychiat Serv 2011; 62: 206-9.

28 Perris C, Rodhe K, Palm A, Hellgren S, Lilja C, Söderman H. Fully integrated in- and outpatient services in a psychiatric sector. Implementation of a new model for the care of psychiatric patients, favouring continuity of care. Soc Psychiatry 1985; 20: 60-9. 